\section{Laboratory tests on the strengthening of wet-mix shotcrete lining with the use of nanomaterials}

Rudarsko-geološko-naftni zbornik

(The Mining-Geology-Petroleum Engineering Bulletin) UDC: 624.1

DOI: 10.17794/rgn.2021.1.5

Original scientific paper

\author{
Hamid Kalhori '; Raheb Bagherpour '; Mohammad Amir Akhlaghi'; \\ Sayed Mohsen Mirdamadi'; Mehdi Nasiri Sarvi ${ }^{1}$ \\ ${ }^{1}$ Department of Mining Engineering, Isfahan University of Technology, Isfahan 8415683111, Iran.
}

\begin{abstract}
Adding nanomaterials to concrete extends the size range of constituent particles well into nano-scale dimensions, which could help the compacting of particles in cement-based materials. Regarding the differences between shotcrete and cast concrete, in this study, the properties of shotcrete with nano and micro-silica and nano-clay were experimentally studied. The micro and nanomaterials have been added at different percentages (6\%, $9 \%$, and $12 \%)$ to a shotcrete paste. The comparison was based on the uniaxial compressive strength, flexural strength, tensile strength, and porosity tests of different specimens. The results indicated that the maximum increase in compressive, flexural, and tensile strengths of shotcrete was related to $12 \%$ nano- $\mathrm{SiO}_{2}$, while for $12 \%$ nano-clay, all of these strengths were decreased at 28 days. The optimum percentage for shotcrete substitution by nano-clay was established to be $6 \%$. Also, the application of the nanomaterials led to a decrease in the water absorption and porosity of shotcrete. Eventually, the results revealed that the improvement of mechanical properties by the introduction of the nanomaterials in shotcrete could be satisfactory.
\end{abstract}

\title{
Keywords:
}

Shotcrete; Micro-silica; Nano-silica; Nano-clay; Mechanical properties.

\section{Introduction}

Concrete is one of the most consumed materials in the world which is widely used as a structural material for numerous forms of structures because of its structural performance and strength characteristics. However, normal concrete has low tensile strength ranges and shows brittle behaviour under tension, which leads to low ductility (Bedeković et al., 2019; T. Zhang and Ren, 2019). Shotcrete is a cement composite that is sprayed on a surface using the hose of a pneumatic nozzle. Shotcrete, also known as sprayed concrete, is applied in different fields such as mining and civil engineering projects, in the stabilization of soil and rock slopes, repairing concrete structures, etc. Also, shotcrete is used as a temporary maintenance system or as part of a permanent maintenance system in underground spaces, tunneling, and mining, sealing stone surfaces, and building tanks and domes. The use of compressed air for applying shotcrete on a target face enables the creation of lots of tiny air voids in it. Generally, air voids in cement-based materials affect their mechanical properties, volume stability, and durability (Abdellah et al., 2020; Choi et al., 2016; Kalhori and Bagherpour, 2017). In addition, in the lining of tunnels, shotcrete is exposed to different risks such as tensile failure, shear failure, sulfate attack,

Corresponding author: Raheb Bagherpour

bagherpour@cc.iut.ac.ir weathering, and freezing and thawing cycles (Zhang et al., 2018).

Due to the very high surface area to volume ratio and the tiny size of nanomaterials, these materials create a suitable adherence with the cement hydrates and improve the many properties of the concrete (Ahmed Sbia et al., 2015; Ozyildirim and Zegetosky, 2010). Also, the utilization of nanomaterials as a replacement of cement in the construction field reduces the mass of used cement and related environmental issues of its production (Vera-Agullo et al., 2009).

Basically, silica nanoparticles (NS) are obtained from micro-based silica. Different studies showed that the addition of NS into concrete improves its physical properties. Considering its spherical shape, it is proven that NS increase the workability of concrete even in low levels of superplasticizer. In addition, the amount of consumed cement decreases when using NS. Controlling the water/ cement ratio, and thus modifying the concrete targeted strength are some other benefits of NS usage (Norhasri et al., 2017). Utilizing nano-silica in concrete enhances its physical properties such as compressive, tensile strength, and flexure strength, and it decreases the water permeability and setting time. It also improves its durability against a chemical attack. For these reasons, nanosilica could be a good choice for use in lots of concrete structures. Even though the high cost of nanoparticles may prevent their widespread application, they are more beneficial than other admixtures (Naji Givi et al., 2010). 
NS increase the micro and nanostructures formed by dispersing in concrete, which results in more condensation of concrete and, consequently, increases its strength (Stefanidou and Papayianni, 2012). Possessing a high content of amorphous silica (over 99\%) and tiny particle size (between 1 and $50 \mathrm{~nm}$ ), amorphous NS has a much better performance than micro-silica, and much less of this nanomaterial has the same pozzolanic effect compared to the high amount of micro-silica (Amiri et al., 2012). Research performed by Jo et al. (2007) represented that the compressive strengths of 7-day and 28day mortars containing nano-silica are higher than those of mortars containing micro-silica. Also, scanning electron micrographs and the residual quantity of calcium hydroxide $\left(\mathrm{Ca}(\mathrm{OH})_{2}\right)$ along with the rate of heat evolution, indicate that nano-silica behaves as an activator in mortars to boost the pozzolanic reaction (Jo et al., 2007).

In an experiment by $\mathbf{L i}$ et al. (2004), a comparison was made between the mortar control samples and samples contained silica foam (SF), nano- $\mathrm{Fe}_{2} \mathrm{O}_{3}(\mathrm{NF})$, and nano-SiO $(\mathrm{NS})$ with different percentages. They observed that the addition of SF, NF, and NS enhanced the strength of 7 and 28 day samples. Scanning electron microscope (SEM) observations also showed that nanoparticles act not only as a nanofiller but also as an activator to improve the hydration and microstructure of the cement mortars (H. Li et al., 2004). Ji (2005) studied the water permeability resistance of concrete containing silica nanoparticles. The results of this study represented that concrete with NS possessed a higher resistance and lower permeability than that of the control concrete. This is due to the fact that the silica nanoparticles can fill the voids which exist in the structure of calcium silicate hydrate (C-S-H) gel and act as nuclei to bond powerfully with (C-S-H) gel particles, which causes the matrix paste to become denser and its durability and physical properties of concrete improves (Ji, 2005). Naji Givi et al. (2010) used 15 and $80 \mathrm{~nm}$ nano-silica in concrete samples as a cement replacement by $0.5,1.0,1.5$, and $2.0 \mathrm{wt} . \%$. They observed that the addition of $15 \mathrm{~nm}$ nano-silica in concrete has a better performance than the $80 \mathrm{~nm}$ in the initial days of curing; this process is changed at 90 days. Furthermore, the results showed that the addition of nano-silica enhanced the compressive, flexural and tensile strength of the concrete samples (Naji Givi et al., 2010). Wang et al. (2018) studied the nano-silica effect on the compressive strength, shrinkage, and sensitivity against cracking, in lightweight aggregate concrete (LWAC) samples. Adding nano-silica significantly increased the 28-day compressive strength of the LWAC (up to a $17 \%$ increase relative to the control sample). In addition, the increased percentage of the nano-silica led to an increase in the compressive strength of LWAC. Adding nano-silica does not significantly affect the long-term shrinkage of concrete. Also, the total cracking areas by adding nano-silica at an early age were reduced. The results of scanning electron microscopy indicated that the addition of nano-silica increased the interfacial transition region between cement paste and aggregates (Wang et al., 2018). Khoshechin and Tanzadeh (2018) expressed that the utilization of nano-silica could stop the penetration of external destructive agents into concrete and increase the stability and strength of concrete. By mixing glass fibers with nanosilica and nano-aluminum, they considered that the compressive and flexural strength of concrete under the best conditions was improved by $20.6 \%$ and $52 \%$, and in shotcrete by $22.9 \%$ and $75 \%$, respectively. These materials enhanced the efficiency of concrete and shotcrete by decreasing the absorption and permeability of water, and by reducing cracking due to shrinkage (Khooshechin and Tanzadeh, 2018).

Nanoclays are nanoparticles that consist of layered mineral silicate. Nanoclays are divided into several groups based on their chemical composition and morphology, such as montmorillonite, kaolinite, halloysite, and hectorite. Clay nanoparticles, recognized as one of the most cost-effective materials, are made of montmorillonite minerals well-known for their platelet structure with an average dimension of about $1 \mathrm{~nm}$ thick and a width of up to $500 \mathrm{~nm}$. The special structure of montmorillonite clay leads to various properties, including stability, swelling capacity, interlayer space, a high level of hydration, and chemical reactions. Typically, montmorillonite is applied in construction materials as an additive to enhance concrete properties. Reports indicated that the addition of nanoclay increases the compressive and tensile strength of mortar cement and improves its thermal behaviour (Norhasri et al., 2017). Adding montmorillonite nanoclay leads to a pozzolanic reaction in Portland cement paste. When montmorillonite nanoparticles are used in cement paste, their nanosheets may be exfoliated in the cement matrix. Therefore clay nanosheets can produce nanoscale layers in the entire cement mortars, which increases the flexural strength (He and Shi, 2008). Research on the effect of nano-kaolin showed that the platelet of nano-metakaolin acts as a fiber between hydration products due to its morphology. SEM images confirmed that nano-metakaolin not only acts as a filler but also as an activator of the hydration process. At $8 \%$ nano-metakaolin replacement, the enhancement of cement mortar was $7 \%$ and $49 \%$ in compressive and tensile strength respectively above the control mortar (Morsy et al., 2010). Kuo et al. (2006) stated that the modified nano-montmorillonite had a dual behaviour in compressive and tensile strength. The addition of about $0.5 \%$ montmorillonite into the cement mortar enhances its compressive and flexural strength by $32 \%$ and $10 \%$ respectively. The higher percentages of the montmorillonite have significantly reduced compressive and flexural strength and the compressive and flexural strength was even smaller than in the control samples (Kuo et al., 2006). Besides, the use of clay nanoparticles can improve the mechanical performance of concrete, the resistance to chloride penetration, the reduction of permeability and shrinkage, and they can in- 
crease the self-compacting properties of concrete (Sanchez and Sobolev, 2010). Shahrajabian and Behfarnia (2018) surveyed the effect of nano-silica, nanoalumina, and nano-clay on the resistance of Alkali-activated slag (AAS) concrete under freeze and thaw conditions. They found nano-silica and nano-clay to be superior to the nano-alumina in the enhancement of the strength and durability of AAS concrete under freezing and thawing cycles. The amount of concrete slump was decreased in the presence of nanomaterials due to the tiny size and higher specific surface of nanoparticles. The greatest slump reduction was observed in samples containing nano-silica and subsequently in samples containing nano-alumina and nano-clay, respectively (Shahrajabian and Behfarnia, 2018).

Considering the aforementioned conditions and the successes attained in applying nanoparticles which affect the physical and chemical properties of concrete, and considering the increased usage of sprayed concrete in mining and construction processes, in this research, the results of nano-silica and nano-clay on improving the characteristics of shotcrete were analyzed and the results were compared with micro-silica. In this research, it was attempted to assess the role of these materials on compressive strength, flexural strength, tensile strength, porosity, and water absorption by shotcrete. The occurrence of significant compressive and flexural spots in the roof and walls of tunnels explains the usage of qualified shotcrete as a requirement.

\section{Materials and methods}

\subsection{Micro and nanomaterials}

To discover the effects of micro and nanomaterials on shotcrete characteristics, silica fume, also known as micro-silica, (SF), nano-silica (NS), and nano-clay (NC) were applied in shotcrete mixtures. The SF and NS were utilized as white and amorphous powders. In this study, the montmorillonite type of $\mathrm{NC}$ was used in the experiments. These particles consist of a platelet structure with an inner octahedral layer sandwiched between two tetrahedral silicates. In other words, the NC particles have one dimension in nano size and the other two dimensions are in micro size. For the purification of montmo- rillonite, a sedimentation method was utilized to achieve purified NC. For physical purification $<1 \mathrm{~mm}$ particles of raw montmorillonite were separated through a centrifuge process. To do this, $12 \mathrm{~g}$ of raw montmorillonite was blended with 400 milliliters of deionized water for 12 hours. The mixture was centrifuged (by Hettich Universal 320 Centrifuge) at $2000 \mathrm{rpm}, 25^{\circ} \mathrm{C}$ for $260 \mathrm{sec}-$ onds. Then, the supernatant was collected as the ultimate product, oven-dried at $85^{\circ} \mathrm{C}$ overnight, and named NC. More details about the purification of $\mathrm{NC}$ are given in (Veiskarami et al., 2016). Table 1 lists the chemical and physical characteristics of SF, NS, and NC. The SEM micrographs of micro and nanoparticles are shown in Figure 1.

\subsection{Mix proportions}

The cement employed in the experiments was Ordinary Portland cement type I (CEM I-32.5), which is produced in the Isfahan Cement Factory located in the center of Iran. The chemical composition of the cement used has been provided in Table 2. Fine aggregate was locally

Table 1: Chemical and physical characteristics of the admixtures

\begin{tabular}{|l|c|c|c|}
\hline $\begin{array}{l}\text { Composition materials } \\
\text { and Physical properties }\end{array}$ & $\begin{array}{c}\text { Micro- } \\
\text {-silica }\end{array}$ & $\begin{array}{c}\text { Nano- } \\
\text {-silica }\end{array}$ & $\begin{array}{c}\text { Nano- } \\
\text {-clay }\end{array}$ \\
\hline $\mathrm{SiO}_{2}(\%)$ & 89.22 & $98 \leq$ & 61.58 \\
\hline $\mathrm{Al}_{2} \mathrm{O}_{3}(\%)$ & 1.20 & 0.076 & 16.59 \\
\hline $\mathrm{Fe}_{2} \mathrm{O}_{3}(\%)$ & 2.12 & 0.293 & 2.47 \\
\hline $\mathrm{CaO}(\%)$ & 1.87 & 0.393 & 3.14 \\
\hline $\mathrm{MgO}(\%)$ & 1.61 & 0.05 & 5.45 \\
\hline $\mathrm{Na}_{2} \mathrm{O}(\%)$ & 0.556 & 0.328 & 0.01 \\
\hline $\mathrm{K}_{2} \mathrm{O}(\%)$ & 1.056 & 0.080 & 0.7 \\
\hline $\mathrm{TiO}_{2}(\%)$ & - & 0.064 & 0.32 \\
\hline $\mathrm{SO}_{3}(\%)$ & - & 0.185 & - \\
\hline $\mathrm{P}_{2} \mathrm{O}_{5}(\%)$ & - & 0.0129 & - \\
\hline $\mathrm{ZnO}(\%)$ & - & 0.021 & - \\
\hline $\mathrm{CuO}(\%)$ & - & 0.020 & - \\
\hline $\mathrm{Specific} \mathrm{surface} \mathrm{area}\left(\mathrm{m}^{2} / \mathrm{gr}\right)$ & 20 & 193 & 95 \\
\hline $\mathrm{Average} \mathrm{particle} \mathrm{size}(\mathrm{nm})$ & $500 \leq$ & $20-30$ & $100-1000$ \\
\hline Density $\left(\mathrm{kg} / \mathrm{m}^{3}\right)$ & 586 & 173 & 230 \\
\hline
\end{tabular}
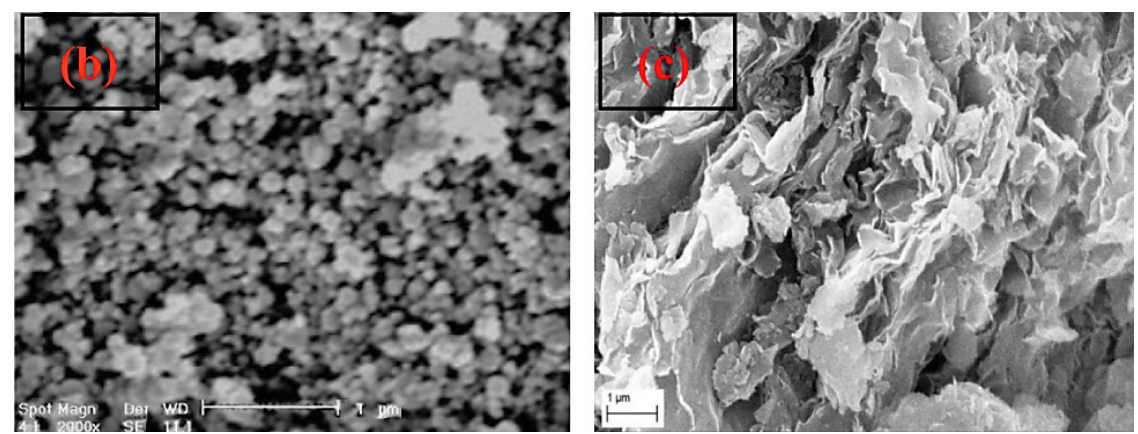

Figure 1: The SEM micrograph of (a) micro-silica; (b) nano-silica; (c) nano-clay particles, magnification 2000 . 


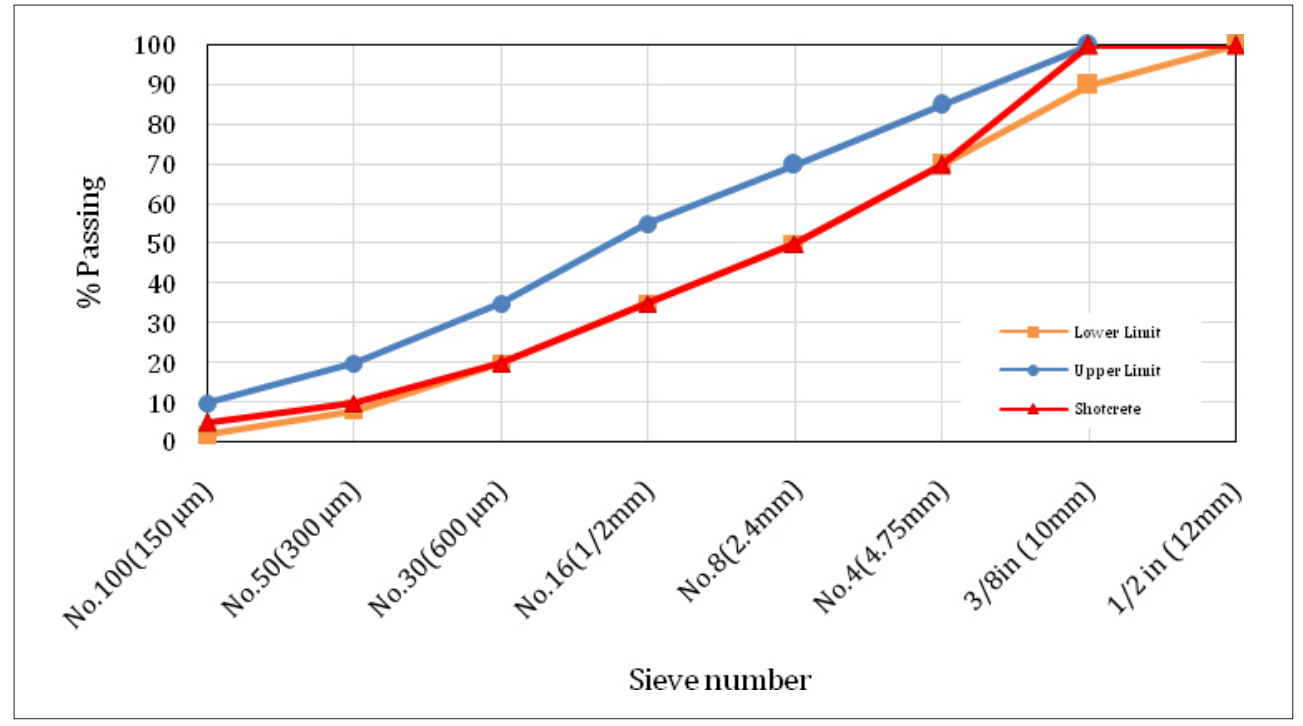

Figure 2: The selective particle size distribution according to the ACI 506R-05 standard

Table 2: Chemical properties of ordinary Portland cement (OPC)

\begin{tabular}{|l|c|c|c|c|c|c|c|c|c|}
\hline Chemical Composition & $\mathbf{S i O}_{2}$ & $\mathbf{A l}_{2} \mathbf{O}_{3}$ & $\mathbf{F e}_{2} \mathbf{O}_{3}$ & $\mathbf{C a O}$ & $\mathbf{M g O}$ & Total Alkalis & $\mathbf{S O}_{3}$ & Insole & L.O.I \\
\hline Constituent (\% wt.) & 22.96 & 4.88 & 3.10 & 61.46 & 2.0 & 0.72 & 2.0 & 0.6 & 1.66 \\
\hline
\end{tabular}

Table 3: Mix compositions.

\begin{tabular}{|l|c|c|c|c|c|c|c|c|c|c|}
\hline \multirow{2}{*}{ mix } & Sand & Cement & $\begin{array}{c}\text { Coarse } \\
\text { aggregate }\end{array}$ & Water & \multicolumn{2}{|c|}{ Micro-silica } & \multicolumn{2}{|c|}{ Nano-silica } & \multicolumn{2}{|c|}{ Nano-clay } \\
\cline { 2 - 12 } & $\mathbf{( k g / \mathbf { m } ^ { 3 } )}$ & $\mathbf{( k g / \mathbf { m } ^ { 3 } )}$ & $\mathbf{( k g / \mathbf { m } ^ { 3 } )}$ & $\mathbf{( k g / \mathbf { m } ^ { 3 } )}$ & $\mathbf{( k g / \mathbf { m } ^ { 3 } )}$ & $\mathbf{\%}$ & $\mathbf{( k g / \mathbf { m } ^ { 3 } )}$ & $\mathbf{\%}$ & $\mathbf{( k g / \mathbf { m } ^ { 3 } )}$ & $\mathbf{\%}$ \\
\hline Control & 1220 & 385 & 523 & 192.5 & 0 & 0 & 0 & 0 & 0 & 0 \\
\hline SF6 & 1220 & 361.9 & 523 & 192.5 & 23.1 & 6 & 0 & 0 & 0 & 0 \\
\hline SF9 & 1220 & 350.4 & 523 & 192.5 & 34.65 & 9 & 0 & 0 & 0 & 0 \\
\hline SF12 & 1220 & 338.8 & 523 & 192.5 & 46.2 & 12 & 0 & 0 & 0 & 0 \\
\hline NS6 & 1220 & 361.9 & 523 & 192.5 & 0 & 0 & 23.1 & 6 & & \\
\hline NS9 & 1220 & 350.4 & 523 & 192.5 & 0 & 0 & 34.65 & 9 & 0 & 0 \\
\hline NS12 & 1220 & 338.8 & 523 & 192.5 & 0 & 0 & 46.2 & 12 & 0 & 0 \\
\hline NC6 & 1220 & 361.9 & 523 & 192.5 & 0 & 0 & 0 & 0 & 23.1 & 6 \\
\hline NC9 & 1220 & 350.4 & 523 & 192.5 & 0 & 0 & 0 & 0 & 34.65 & 9 \\
\hline NC12 & 1220 & 338.8 & 523 & 192.5 & 0 & 0 & 0 & 0 & 46.2 & 12 \\
\hline
\end{tabular}

available, a well-graded washed river sand with a specific gravity of 2.65 , a fineness modulus of 2.90 , and a maximum grain size of $4.75 \mathrm{~mm}$. The coarse aggregate was crushed sedimentary stone (dolomite) with the particle size in the range of $4.75-10 \mathrm{~mm}$ and a specific gravity of 2.70 . The shotcrete mix design was calculated in compliance with ACI 506R-05 to have a 28-day compressive strength of $28 \mathrm{MPa}$. Table 3 shows the mixed compositions of control samples with the w/c ratio of 0.5. In order to obtain a suitable dispersion of admixtures in the cement matrix, those were firstly mixed with some of the water, and then the resulting mixture was poured into the shotcrete mix. A polycarboxylate-based superplasticizer and accelerator were employed to ob- tain better workability. Figure 2 indicates the selective particle size distribution according to the ACI 506R-05 standard (ACI Committee 506, 2005).

The mixing design mentioned above was applied for the preparation of the control samples. In this study, the cement was replaced by micro-silica (SF), nano-silica (NS), and nano-clay (NC) with $6 \%, 9 \%$, and $12 \%$ by weight of cement for samples preparation. Therefore, in total ten different mixing designs were prepared in this project. The first mixing design is of the control samples. The other nine mixing designs are mixes made according to Table 3, where the amount of the mentioned particles were substituted by the cement. The coding of the samples is illustrated in Table 3. 


\subsection{Spraying process and specimen preparation}

The test panels were made from wood with a width and length of $610 \mathrm{~mm}$ and a depth of $100 \mathrm{~mm}$ following the ASTM C1140 standard (ASTM-C1140). Panels were oriented at 45-degrees to the horizontal and the nozzle tip direction was about perpendicular to the surface of the panel. In Figure 3, some of the wooden panels and their placement position are shown. According to each mix design, materials were blended in an automatic mixer and the resulting shotcrete mixture was discharged into the tank of a wet mix shotcreting machine (model T13) which was manufactured by Tiran Tunnel Biston Co. (see Figure 4). After that, the spraying process was performed on the panels. Then, wet covers were spread on the surface of all shotcrete panels. After $24 \mathrm{~h}$, the shotcrete slabs were removed from the molds and the sampling process was performed. The diameter of the drilled cores was $54 \mathrm{~mm}$ and the end parts of the samples were rubbed and polished according to ASTM C39 (ASTM-C39).

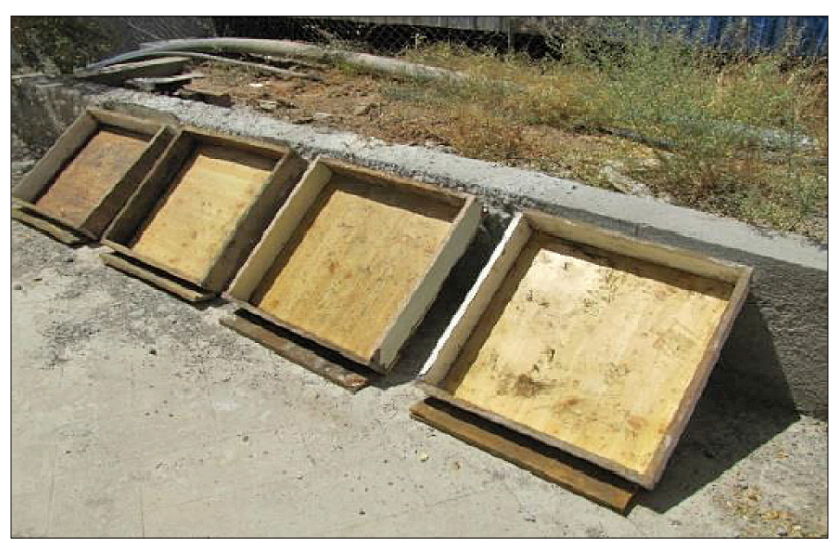

Figure 3: Shotcrete panels

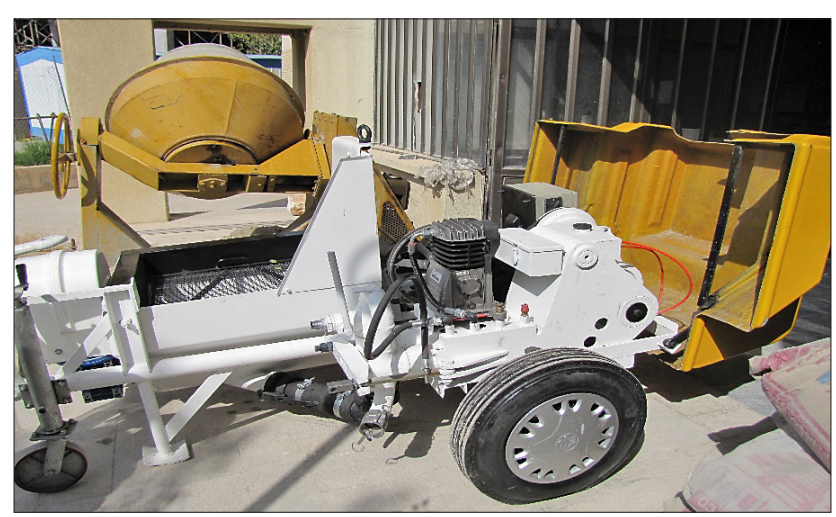

Figure 4: Wet mix shotcreting machine (model $\mathrm{T}_{13}$ )

\subsection{Samples curing}

Curing the shotcrete is one of the most critical actions after the shotcreting process. Shotcrete needs to be cured to reach its highest possible strength, and failing to do so leads to the emergence of cracks, reduced ultimate strength, and reduced performance of shotcrete. Typical water curing of concrete includes keeping the surface of the concrete humid through the use of immersion, ponding, spraying, wet covering, etc. For shotcrete, the immersion and ponding methods cannot be used in operation fields. Still, the use of a damp blanket by water-absorbent fabrics to create a humid environment on the surface and water spraying can be somewhat possible. According to the ACI506R-06 standard, the best conditions for the curing of shotcrete is to keep it wet for seven days (maintaining a temperature over $5^{\circ} \mathrm{C}$ ). The water applied to cure the shotcrete, should not be more than $10^{\circ} \mathrm{C}$ cooler relative to the surface of the shotcrete when the water and shotcrete come into contact. In this research, after shotcreting, slabs were covered with wet burlap and plastic wraps. During the curing time, water was sprayed on the burlap twice a day, and the surface of the shotcrete samples was always kept wet. This type of curing is feasible and straightforward in performance conditions. For experiments, the slabs were removed from the panels and cut into different sizes using an automatic rock cutting machine or they were cored.

\subsection{Test procedure}

\subsubsection{Compressive strength}

The uniaxial compressive strength test is the most well-known experiment for the examination of the mechanical characteristics of shotcrete in most construction plans. Cylindrical cores with a diameter of $54 \mathrm{~mm}$ were obtained from the shotcrete panels in accordance with the ASTM C1604 standard due to the measurement of the 28-day compressive strength of the samples (ASTMC1604/C1604M). Also, cubic samples with dimensions of $10 \mathrm{~cm}$ were saw-cut from the slabs. The compressive strength experiment was conducted on cylindrical samples as well as cubic samples. The saturated samples with dry surfaces were set in the uniaxial compressive test device and were exposed to a controlled loading without any shock. The loading process was done with a continuous increase with a constant rate on the sample until visible cracks emerged on the sample surfaces and no higher load could be tolerated. Three specimens per batch were tested and the average strength was reported.

\subsubsection{Flexural strength}

Flexural strength is an indirect test for the measurement of the concrete tensile strength. In this examination, beam specimens with a size of $100 \times 100 \times 350 \mathrm{~mm}$ were utilized for the Flexural test according to ASTM C78-00, and the experiment was conducted to assess flexural strength (ASTM-C78-00, 2010). According to the standard, if a crack starts in the tension surface within the middle third of the span length, calculate the flexural strength as equation (1) and if the fracture occurs in the tension surface out of the middle third of the span 
length by less than $5 \%$ of the span length, calculate the flexural strength as equation (2).

$$
\begin{aligned}
& F=\frac{P L}{B H^{2}} \\
& F=\frac{3 P A}{B H^{2}}
\end{aligned}
$$

Where:

$$
\begin{aligned}
& P \text { - The maximum applied load is shown by the test- } \\
& \quad \text { ing machine }(\mathrm{N}), \\
& L \text { - Span length }(\mathrm{mm}), \\
& B \text { - Average width of the sample }(\mathrm{mm}), \\
& H \text { - Average depth of sample (mm), } \\
& A \text { - Average distance between the line of fracture and } \\
& \text { the nearest support measured on the tension face } \\
& \quad \text { of the beam (mm), } \\
& F \text { - Flexural strength (MPa). }
\end{aligned}
$$

\subsubsection{Indirect tensile test}

The Brazilian test known as an indirect tensile test was conducted, in accordance with ISRM standard, on disc-shaped samples with a size of $54 \mathrm{~mm}$ in diameter and $27 \mathrm{~mm}$ in length. 28-day shotcrete samples were set under the device so that the central axis of the samples placed in horizontal state and load should be applied uniformly on the body of the sample at both ends of a diameter. With this fixture, it was guaranteed that the tensile load was exerted on the diagonal axis located among the two loading tracks. The samples would also be fractured from this axis. In this experiment, the interface between the sample and the loading surface should be quite smooth, and the sample must have the same diameter at both ends. The fracture mechanism in the Brazilian test is illustrated in Figure 5. An average of ten examinations on samples were performed for tensile strength measurement.

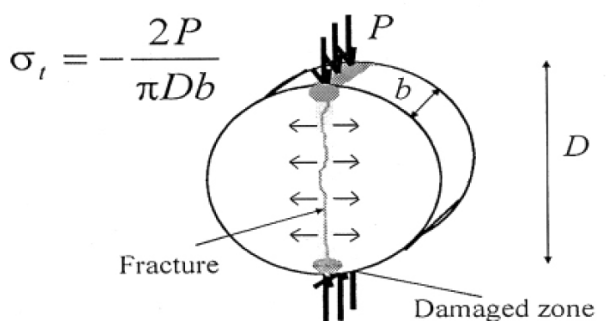

Figure 5: Mechanism of fracture in Brazilian test (D. Li et al., 2013).

\subsubsection{Density test and porosity test}

The porosity and density measurement procedures were performed according to the ISRM standard. The saturated mass $\left(\mathrm{M}_{\mathrm{sat}}\right)$ was calculated by immersing spec- imens for about 48 hours in almost $21^{\circ} \mathrm{C}$ water, determining a mass equilibrium of less than $0.5 \%$ among two evaluations at 24-hour intervals. The dry mass of the sample $\left(\mathrm{M}_{\text {dry }}\right)$ was calculated by oven-drying at $105^{\circ} \mathrm{C}$. The sample mass was estimated in 24-hour intervals until the variation among two consecutive measurements was attained to less than $0.5 \%$. Due to the regular geometric form of the samples, the dimensions of the sample were measured by a caliper up to $0.1 \mathrm{~mm}$, and the volume of samples (V) was obtained. Density and porosity were then obtained from equations (3) and (4):

$$
\begin{gathered}
\rho=\frac{M}{V} \\
n=\frac{\left(M_{s a t}-M_{d r y}\right) / \rho_{w}}{V}
\end{gathered}
$$

Where:

$\rho$ - The density of the initial sample,

$M$-The initial mass of the sample,

$n$ - The porosity and $\rho_{w}$ is the density of water,

For each batch according to the standard, three samples were probed and measured (ISRM, 1979).

\section{Results and Discussion}

\subsection{Uniaxial compressive strength}

The test results from the uniaxial compressive strength core drilled samples, in 10 various mixing designs, are illustrated in Figure 6. All the tests were conducted in triplicates and the outcomes are presented as means \pm standard deviation. The results show that micro-silica (SF) and nano-silica (NS) increase the compressive strength of shotcrete, compared to the control sample. This trend can be seen for all percentages. The uniaxial compressive strength improvement caused by NS is higher than SF, which indicates a better micro filling feature, a higher pozzolanic property, and more suitable nucleation characteristics of NS compared to SF. In samples containing NS, the compressive strength is enhanced by increasing the NS content. The same trend is recognized in specimens containing SF. The compressive strength of specimens containing $12 \%$ SF were higher than the control samples, however, its uniaxial compressive strength declined in comparison to the specimens containing $9 \% \mathrm{SF}$, meaning the high amounts of SF caused an incomplete hydration result as well as a reduction in compressive strength of shotcrete in these experiments. When the content of SF increased, likely SF particles were not combined properly with other shotcrete ingredients and so an incomplete distribution was made in the shotcrete mixture. Therefore, SF particles might be agglomerated and weak regions formed in the shotcrete. As a result, in these experiments, the optimum SF threshold was achieved as $9 \%$. The investiga- 
tion results of other researchers on the effects of SF on the compressive strength of concrete indicated it as an optimal percentage in the mixture (Hanumesh et al., 2015; Ismeik, 2009; H. A. Mohamed, 2011). The compressive strength of the specimens including nano-clay (NC) was decreased by increasing the NC percentage. The results obtained from the experiments for specimens containing NC showed that the addition of $6 \%$ clay nanoparticles caused an increase in the compressive strength of the samples by about $10 \%$, while the samples containing $9 \%$ NC possessed a compressive strength similar to the control sample, and the compressive strength of the specimens containing $12 \% \mathrm{NC}$ was about $6 \%$ less than the control specimen. The dual behaviour of NC is because of (1) the filling property and pozzolanic activity of this material, and (2) the high water absorption feature and the interruption in the formation process when producing calcium silicate hydrate (C-S$\mathrm{H})$ gel. In other words, the pozzolanic activity and porefilling property occur in NC content of $6 \%$. The compressive strength decreased dramatically by increasing the replacement ratio of $\mathrm{NC}$ to $12 \%$ due to the increasing the content of NC cause the disruption in producing the (C-S-H) gel as well as the increasing amount of clay nanoparticles agglomeration. The same trend has been reported by some other articles (Hosseini et al., 2017; A. M. Mohamed, 2016). In general, all materials in the content of $6 \%$ increased the compressive strength. In $6 \%$ content, the compressive strength of the samples contained SF, NS, and NC and was improved by about $16 \%$, $18 \%$, and $10 \%$, respectively.

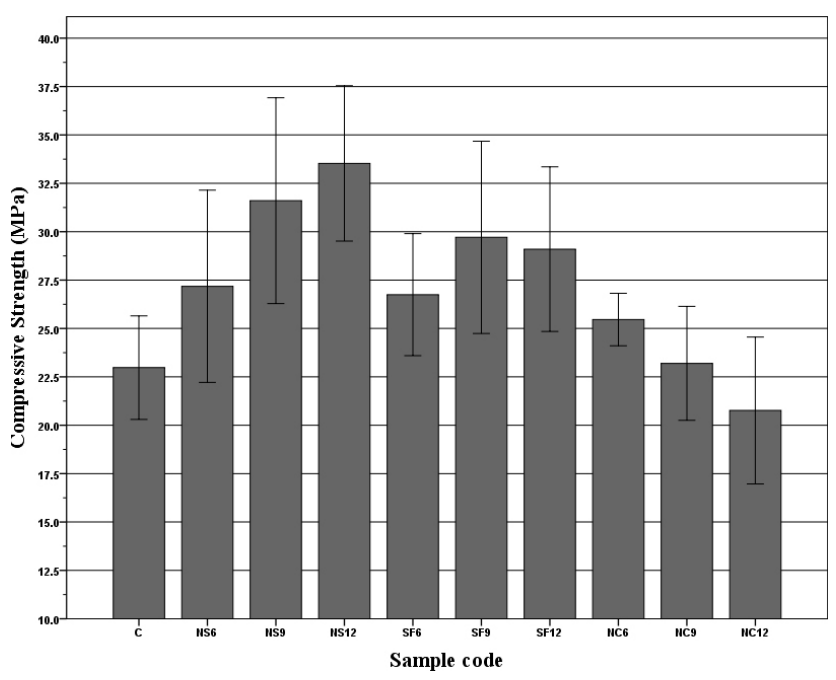

Figure 6: Compressive strength of cylindrical shotcrete specimens.

To examine the accuracy of the uniaxial compressive strength experiments of the core drilled samples and to calculate the ratio of compressive strength of the cube samples to cylindrical samples, the cubic samples were also examined. Cube samples with dimensions of $70 \mathrm{~mm}$ were tested by an Unconfined Compression Test Machine. The results are illustrated in Figure 7.

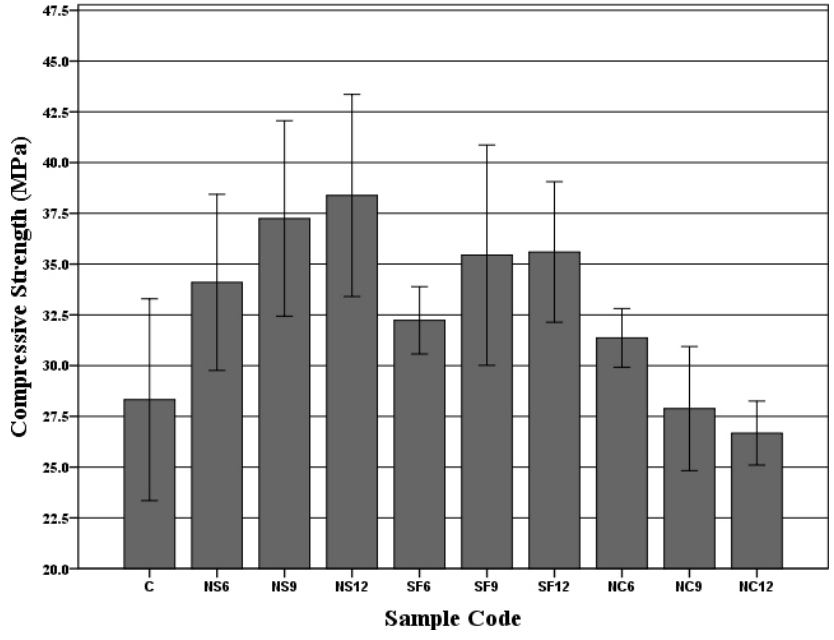

Figure 7: Compressive strength of cube shotcrete specimens.

Figure 7 indicates results similar to those obtained from the compressive strength of the core drilled samples. All the tests were conducted in triplicate and the outcomes are presented as means \pm standard deviation. With respect to this figure, the compressive strengths of cubic samples are higher than similar cored samples. The ascending or descending behaviour of NS and NC samples is similar to the results of the core drilled specimens. In the core drilled samples, the compressive strength in the presence of $12 \% \mathrm{SF}$ was less than $9 \% \mathrm{SF}$. As a result, $9 \%$ of SF was chosen as the optimal amount. In the results obtained from the compressive strength experiment of the cubic samples, a $12 \%$ SF exhibited a negligible enhancement in compressive strength versus the sample containing $9 \% \mathrm{SF}$. Taking into account the amount of increased compressive strength of these samples and the cost of SF, 9\% SF is considered as the optimum amount of the SF. The average compressive strength ratio of core drilled samples to the cube samples in 10 different batches was in the range of 0.78-0.87. A broken cube sample in a uniaxial compression test is shown in Figure 8.

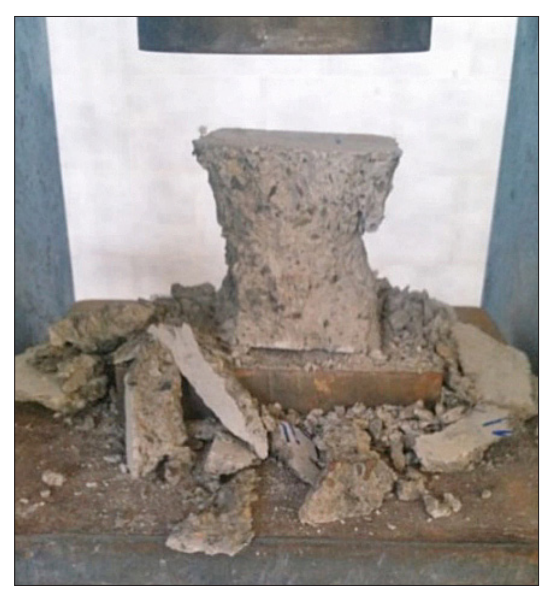

Figure 8: A broken cube sample in a uniaxial compression test 


\subsection{Flexural strength}

The results of the flexural strength experiment of the various shotcrete specimens after 28 days are presented in Figure 9. All the tests were conducted in triplicate and the outcomes are presented as means \pm standard deviation. The results indicate that micro and nano-silica caused an increase in the shotcrete flexural strength at all percentages, compared to the control sample. The behaviour of samples containing SF and NS under the flexural loading are very close together. By increasing the percentage of SF and NS, the flexural strength of the shotcrete was increased. The use of common fibers has been recommended for enhancing the flexural strength of the shotcrete and improving its behaviour after the ultimate strength point in the stress-strain curve. However, by increasing the density and adhesion ability of the shotcrete components, as well as improving the calcium silicate gel hydride (C-S-H) in the shotcrete, a better coherence in the shotcrete was created, and flexural strength was increased. By increasing the percentage of $\mathrm{NC}$, the flexural strength of the shotcrete was reduced. When the amount of the additives became $6 \%$, the flexural strength increased in all samples compared to the control sample. Montmorillonite consists of a plate-

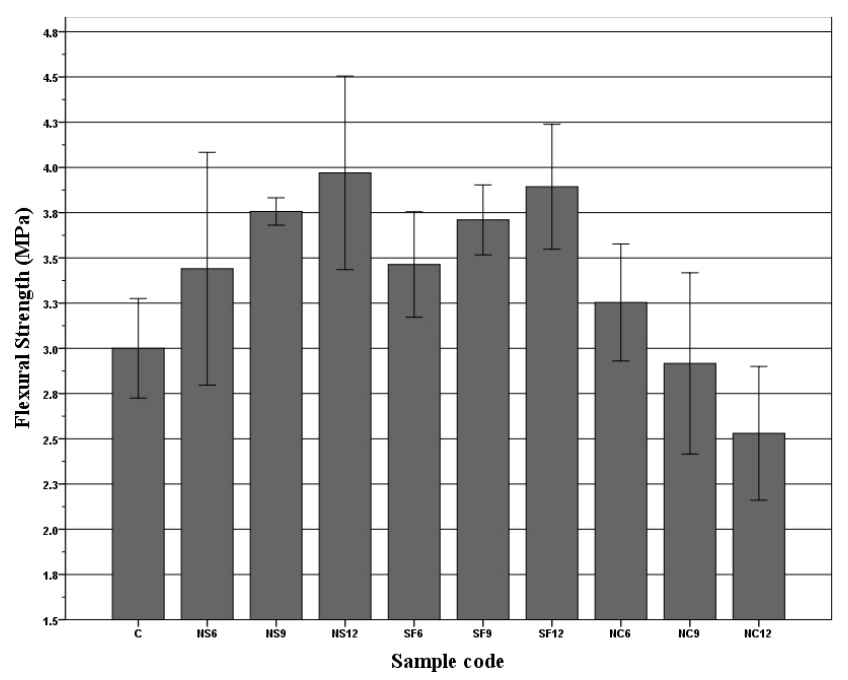

Figure 9: Flexural strength of shotcrete specimens.

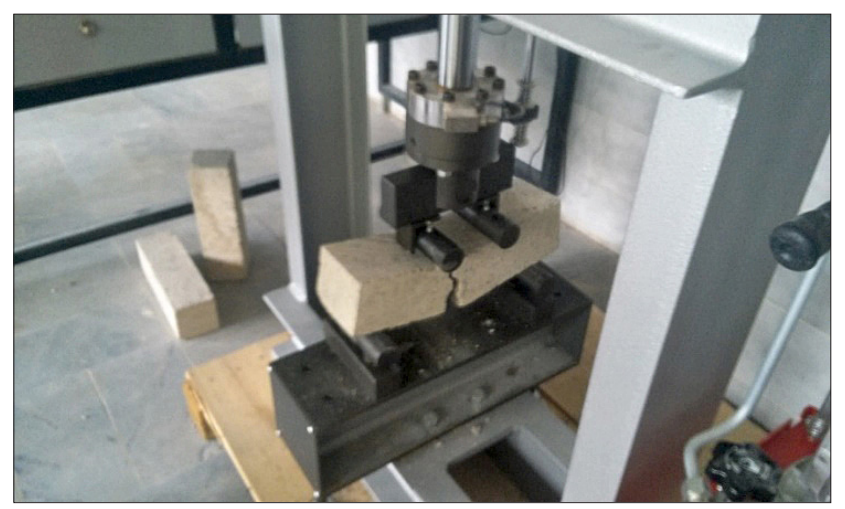

Figure 10: A broken prismatic sample in a flexural test. shaped structure and this architecture has been claimed to prevent crack propagation and could improve the flexural strength consequently (Mortazavi et al., 2012). When the amount of NC became $9 \%$, the flexural strength was somewhat less than that of the control sample, and in $12 \%$ of the $\mathrm{NC}$, the flexural strength reduction was about $15 \%$. A sample which was broken under the influence of flexural load is shown in Figure 10.

\subsection{Indirect tensile}

The results of an indirect tensile test in various shotcrete samples after 28 days are presented in Figure 11. The reported values are the average amounts of $10 \mathrm{ex}-$ amined samples. The general behaviour of the samples in the Brazilian test is similar to the flexural test because, in both tests, the tensile strength of the shotcrete is measured by two different standard methods. The tensile strengths achieved from the flexural test are higher than the tensile strengths obtained from the Brazilian tensile test. In the Brazilian test, specimens with NS show better tensile strengths compared to the samples containing SF. In samples containing nano and micro-silica, by increasing the percentage of additives, the indirect tensile strength has also been increased. When the amount of the additives became $6 \%$, the tensile strength of all samples was increased. In samples containing $6 \% \mathrm{NC}$, regarding the reasons mentioned above, these nanoparticles improved the tensile strength and in contrast to the content of 9 and 12 percent of NC, because of the consumed addition of $\mathrm{NC}$, a reduction in tensile strength was observed.

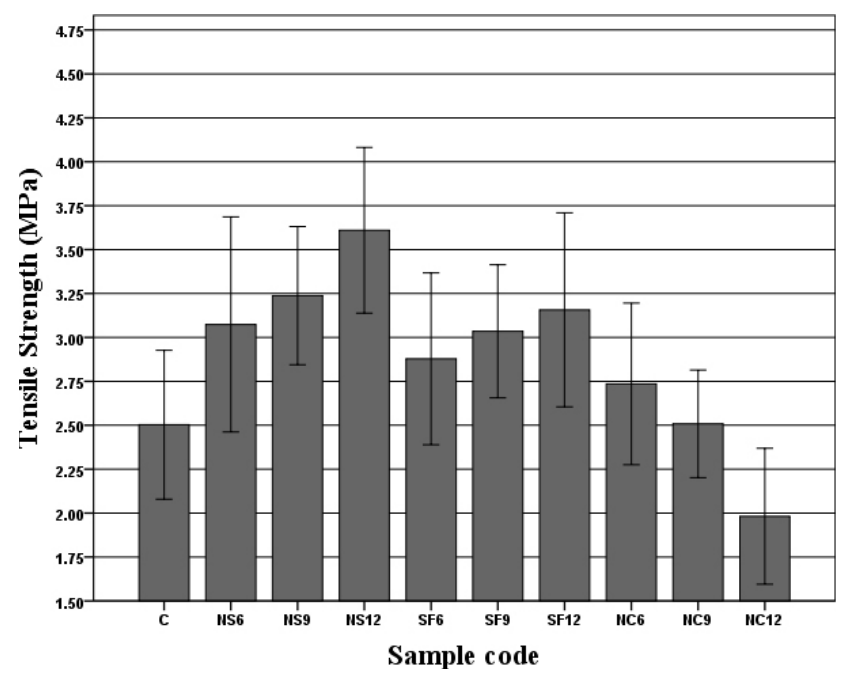

Figure 11: Tensile strength of shotcrete specimens at 28 days.

\subsection{Density and porosity}

According to the ISRM standard, the density and porosity of the samples were examined and calculated. All the tests were conducted in triplicate and the outcomes are presented as means \pm standard deviation. The results of the density calculations are shown in Figure 12. As 


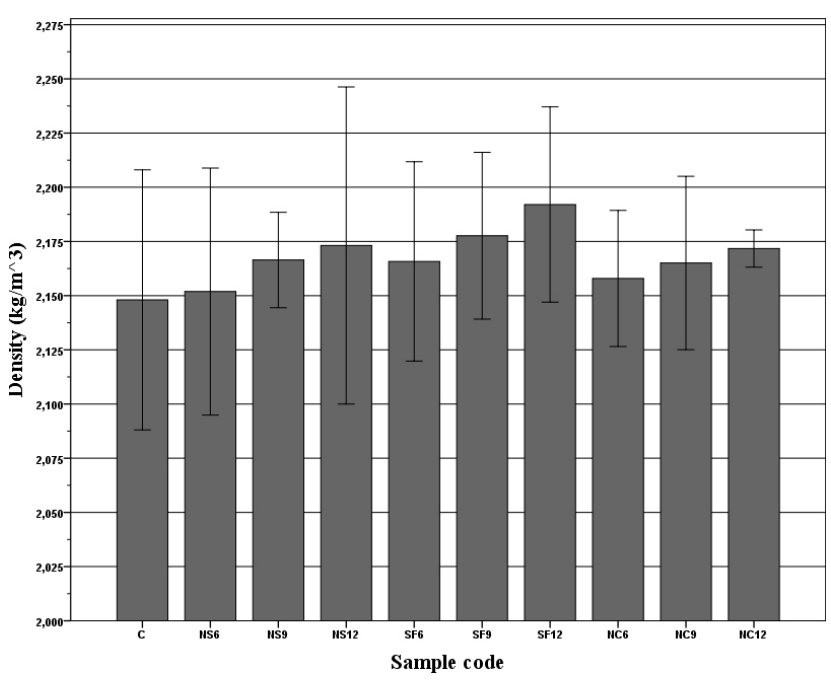

Figure 12: The density of the shotcrete samples.

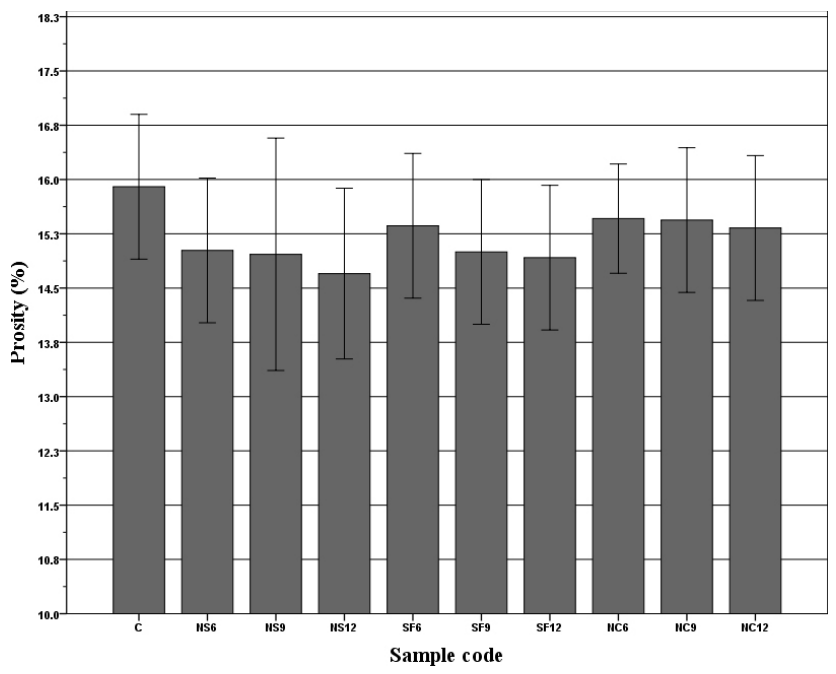

Figure 13: The porosity of the shotcrete samples.

already explained, the reasons for the application of pozzolanic particles in shotcrete are their pore-filling property as well as pozzolanic activity. As a result, all nanoparticles, regardless of their matter, if they possess the ability to mix with the shotcrete components and are dispersed throughout the shotcrete mortar, they cause an increase in the density of shotcrete. Micro and nanoparticles are distributed throughout the shotcrete mortar and fill the microstructures; this leads to an increase shotcrete density. As a result, it has been observed that the density of all samples containing micro and nanoparticles possess a higher density than the control sample. It is worthy to note that the use of these pozzolanic admixtures as a replacement for cement did not significantly change the shotcrete density. These admixture particles are more lightweight than cement particles, so utilizing those instead of cement causes the density of the shotcrete specimens to decline. Therefore, the overall density of specimens has not changed much. These results illustrate good conformity with the research results of Fallah and Nematzadeh (Fallah and Nematzadeh,
2017). The sensible increment in the density of specimens containing SF in comparison to other materials is because of the higher density of SF. The results of the porosity experiment are shown in Figure 13. According to the above description of density, the porosity of the samples is reduced by the addition of nanomaterials, which is completely clear in the above figure. In addition to filling the microstructures, NS reacts with cement paste regarding its severe pozzolanic properties; this causes the C-S-H gel to be denser. Considering the water absorption feature of clay, the NC lost some water during the drying of the sample, and this phenomenon causes a greater porosity in the sample. The obtained results of the porosity of different shotcrete batches have a good adaptation with the results of the strength properties of specimens. The reduction of porosity and water absorption will make shotcrete a suitable protecting layer on a tunnel roof where there may be water leakage issues.

\section{Conclusions}

The most important results of this study could be reviewed as follows:

The uniaxial compressive strength trends of all batches propose that the use of the pozzolanic admixtures enhances the compressive strength of shotcrete except $12 \%$ NC. Nano-silica performed more efficiently in promoting the compressive strength and enhanced the 28day compressive strength up to $46 \%$ compared to the control specimen. The results showed that the compressive strength was enhanced by incrementing the content of NS up to $12 \%$, although the optimal content of SF and NC were $9 \%$ and $6 \%$ respectively. The application of high content of SF and NC reduced their performance; which could be linked to material agglomeration, pore generation phenomena and a disturbance in the production of C-S-H gel.

The results of the flexural and Brazilian tensile tests in different shotcrete samples exhibited similar behaviour. The specimens containing NS demonstrated higher flexural and tensile strengths compared to the samples containing SF and NC. A maximum flexural strength improvement was related to samples with $12 \% \mathrm{NS}$ up to $32 \%$. However, the specimens containing $12 \% \mathrm{NC}$ showed a $15 \%$ reduction in flexural strength. In samples containing $6 \% \mathrm{NC}$, regarding greater coherence of the shotcrete mortar as a result of the filling property of the nanoparticle and the plate-shaped NCs, these particles improved the flexural strength until they disrupted the $(\mathrm{C}-\mathrm{S}-\mathrm{H})$ gel. In percentages of 9 and 12 percent of $\mathrm{NC}$, considering the larger addition of $\mathrm{NC}$, and the disruption of the (C-S-H) gel, the effect of the particles' plate shape was lost, and a disruption created in the $(\mathrm{C}-\mathrm{S}-\mathrm{H})$ gel was exhibited. Generally, $6 \%$ of the content of all additives enhanced the tensile and flexural strength of shotcrete.

The addition of micro and nanoparticles decrease the porosity of shotcrete due to the tiny size and high spe- 
cific surface as well as the great pozzolanic activities of these materials. Micro and nano-silica caused a greater porosity decrease compared to nano-clay. The reason could be related to the better pozzolanic reaction of SF and NS, resulting in the creation of a strong C-S-H gel. The same trend was observed regarding the density of various specimens. Therefore, the stability of shotcrete constructions could be enhanced by the appropriate application of the pozzolanic admixtures.

It can be concluded that nano-silica has a significant improvement in the mechanical and physical properties of shotcrete; also, nano-clay in a low percentage substituted by cement would have helpful effects on shotcrete characteristics. Due to the favorable impact of nano-clay and its low cost, using it, especially on critical compressive and flexural zones in the roof and walls of tunnels, will enhance the performance of tunnel lining.

\section{References}

Elrawy, W.R., Abdelhaffez, G.S. Saleem, H.A. (2020): Stability assessment of underground openings using different rock support systems. Rudarsko-geološko-naftni zbornik (The Mining-Geology-Petroleum Engineering Bulletin), $35,1,49-63$.

ACI 506R-05 (2005): ACI standard 506R-05 - Guide to shotcrete, ACI Committee, American Concrete Institute, www. concrete.org.

Ahmed Sbia, L., Peyvandi, A., Soroushian, P., Balachandra, A. M., and Sobolev, K. (2015): Evaluation of modifiedgraphite nanomaterials in concrete nanocomposite based on packing density principles. Construction and Building Materials, 76, 413-422.

Amiri, B., Bahari, A., Nik, A.S., Nik, A.S., and Movahedi, N.S. (2012): Use of AFM technique to study the nano-silica effects in concrete mixture. Indian Journal of Science and Technology, 5, 2, 2055-2059.

ASTM C39 (2001): Standard test method for compressive strength of cylindrical concrete specimens, ASTM International, West Conshohocken, PA, www.astm.org.

ASTM C1140 (2011): Standard Practice for Preparing and Testing Specimens from Shotcrete Test Panels, ASTM International, West Conshohocken, PA, www.astm.org.

ASTM C1604 / C1604M (2005): Standard Test Method for Obtaining and Testing Drilled Cores of Shotcrete, ASTM International, West Conshohocken, PA, www.astm.org.

ASTM C78 / C78M (2010).Standard test method for flexural strength of concrete (using simple beam with third-point loading), ASTM International, West Conshohocken, PA, www.astm.org.

Bedeković, G., Grčić, I., Anić Vučinić, A., and Premur, V. (2019): Recovery of waste expanded polystyrene in lightweight concrete production. Rudarsko-geološko-naftni zbornik (The Mining-Geology-Petroleum Engineering Bulletin), 34, 3, 73-80.

Choi, P., Yeon, J.H., Yun, K.K. (2016): Air-void structure, strength, and permeability of wet-mix shotcrete before and after shotcreting operation: The influences of silica fume and air-entraining agent. Cement and Concrete Composites, 70, 69-77.

Fallah, S., and Nematzadeh, M. (2017): Mechanical properties and durability of high-strength concrete containing macropolymeric and polypropylene fibers with nano-silica and silica fume. Construction and Building Materials, 132, 170-187.

Hanumesh, B., Varun, B., Harish, B. (2015): The mechanical properties of concrete incorporating silica fume as partial replacement of cement. International Journal of Emerging Technology and Advanced Engineering, 5, 9, 270.

He, X., and Shi, X. (2008): Chloride permeability and microstructure of Portland cement mortars incorporating nanomaterials. Transportation Research Record: Journal of the Transportation Research Board, 2070, 1, 13-21.

Hosseini, P., Afshar, A., Vafaei, B., Booshehrian, A., Molaei Raisi, E., Esrafili, A. (2017): Effects of nano-clay particles on the short-term properties of self-compacting concrete. European Journal of Environmental and Civil Engineering, 21, 2, 127-147.

Ismeik, M. (2009): Effect of mineral admixtures on mechanical properties of high strength concrete made with locally available materials. Jordan Journal of Civil Engineering, 3, 1, 78-90.

I.S.R.M. (1979): Suggested Methods for Determining Water Content, Porosity, Density, Absorption and Related Properties and Swelling and Slake-durability Index Properties. International Society for Rock Mechanics, Commission on Standardization of Laboratory and Field Tests, Pergamon, $1-36$.

Ji, T. (2005): Preliminary study on the water permeability and microstructure of concrete incorporating nano-SiO2. Cement and Concrete Research, 35, 10, 1943-1947.

Jo, B.W., Kim, C.H., Tae, G.H., and Park, J.B. (2007): Characteristics of cement mortar with nano-SiO2 particles. Construction and Building Materials, 21, 6, 1351-1355.

Kalhori, H., and Bagherpour, R. (2017): Application of carbonate precipitating bacteria for improving properties and repairing cracks of shotcrete. Construction and Building Materials, 148(Supplement C), 249-260.

Khooshechin, M., and Tanzadeh, J. (2018): Experimental and mechanical performance of shotcrete made with nanomaterials and fiber reinforcement. Construction and Building Materials, 165, 199-205.

Kuo, W.Y., Huang, J.S., and Lin, C.H. (2006): Effects of organo-modified montmorillonite on strengths and permeability of cement mortars. Cement and Concrete Research, 36, 5, 886-895.

Li, D., Wong, L.N.Y. (2013): The Brazilian disc test for rock mechanics applications: review and new insights. Rock mechanics and rock engineering, 46, 2, 269-287.

Li, H., Xiao, H.G., Yuan, J., Ou, J. (2004): Microstructure of cement mortar with nano-particles. Composites Part B: Engineering, 35, 2, 185-189.

Mohamed, A.M. (2016): Influence of nano materials on flexural behaviour and compressive strength of concrete. HBRC journal, 12, 2, 212-225. 
Mohamed, H.A. (2011): Effect of fly ash and silica fume on compressive strength of self-compacting concrete under different curing conditions. Ain Shams Engineering Journal, 2, 2, 79-86.

Morsy, M., Alsayed, S., Aqel, M. (2010): Effect of nano-clay on mechanical properties and microstructure of ordinary Portland cement mortar. International Journal of Civil \& Environmental Engineering IJCEE-IJENS, 10, 01, 23-27.

Mortazavi, V., Atai, M., Fathi, M., Keshavarzi, S., Khalighinejad, N., Badrian, H. (2012): The effect of nanoclay filler loading on the flexural strength of fiber-reinforced composites. Dental research journal, 9, 3, 273.

Naji Givi, A., Abdul Rashid, S., Aziz, F.N.A., Salleh, M.A.M. (2010): Experimental investigation of the size effects of $\mathrm{SiO} 2$ nano-particles on the mechanical properties of binary blended concrete. Composites Part B: Engineering, 41, 8, 673-677.

Norhasri, M.S.M., Hamidah, M.S., and Fadzil, A.M. (2017): Applications of using nano material in concrete: A review. Construction and Building Materials, 133, 91-97.

Ozyildirim, C., and Zegetosky, C. (2010): Exploratory investigation of nanomaterials to improve strength and permeability of concrete. Transportation Research Record: Journal of the Transportation Research Board, 2142, 1-8.

Sanchez, F., and Sobolev, K. (2010): Nanotechnology in concrete-a review. Construction and Building Materials, 24, 11, 2060-2071.

Shahrajabian, F., and Behfarnia, K. (2018): The effects of nano particles on freeze and thaw resistance of alkali-activated slag concrete. Construction and Building Materials, 176, 172-178.

Stefanidou, M., and Papayianni, I. (2012): Influence of nano$\mathrm{SiO} 2$ on the Portland cement pastes. Composites Part B: Engineering, 43, 6, 2706-2710.

Veiskarami, M., Sarvi, M.N., Mokhtari, A.R. (2016): Influence of the purity of montmorillonite on its surface modification with an alkyl-ammonium salt. Applied Clay Science, 120, 111-120.

Vera-Agullo, J., Chozas-Ligero, V., Portillo-Rico, D., GarcíaCasas, M., Gutiérrez-Martínez, A., Mieres-Royo, J., and Grávalos-Moreno, J. (2009). Mortar and concrete reinforced with nanomaterials. In: Nanotechnology in Construction 3, Springer, 383-388.

Wang, X.F., Huang, Y.J., Wu, G.Y., Fang, C., Li, D.W., Han, N.X., and Xing, F. (2018): Effect of nano-SiO2 on strength, shrinkage and cracking sensitivity of lightweight aggregate concrete. Construction and Building Materials, 175, 115-125.

Zhang, T., and Ren, Y. (2019): Identification and detection of a void under highway cement concrete pavement slabs based on finite element analysis. Rudarsko-geološkonaftni zbornik (The Mining-Geology-Petroleum Engineering Bulletin), 34, 3, 41-47.

Zhang, Z., Jin, X., and Luo, W. (2018): Mechanical responses of shotcrete specimens in direct shear tests. Construction and Building Materials, 188, 305-313.

\section{SAŽETAK}

\section{Laboratorijski test čvrstoće mlaznoga betona dobivenoga mokrim postupkom uporabom nanomaterijala}

Dodavanje nanomaterijala betonu proširuje veličinu čestica od kojih se on sastoji prema nanodimenzijama. To može pomoći zbijanju takvih materijala. Usporedbom razlika između mlaznoga i lijevanoga betona, načinjenom u ovoj studiji, eksperimentalno su istražena svojstva mlaznoga betona kojemu su dodane nano i mikro silikatne te glinovite čestice. Mikromaterijali i nanomaterijali dodani su u različitim postotcima (6, 9 i 12 \%) u masu betona. Usporedba je načinjena promatranjem jednoosne kompresijske čvrstoće, čvrstoće na svijanje i smicanje te opažanjem šupljikavosti različitih uzoraka. Rezultati su pokazali kako je najveće povećanje navedenih čvrstoća mlaznoga betona postignuto dodavanjem 12-postotnoga nanosilikata, a najveći pad s 12-postotnom nanoglinom, nakon 28 dana. Primjena nanomaterijala dovela je i do smanjenja apsorpcije vode i šupljikavosti. Poboljašanje svojstava mlaznoga betona dodavanjem nanomaterijala ocijenjeno je zadovoljavajućim.

\section{Ključne riječi:}

mlazni beton, mikrosilikati, nanosilikati, nanogline, mehanička svojstva

\section{Author's contribution}

Hamid Kalhori, the Ph.D. student, contributed to the performing experiments; Raheb Bagherpour, Full Professor, performed the design and implementation of the research; Mohammad Amir Akhlaghi, the Ph.D. student, wrote the manuscript; Sayed Mohsen Mirdamadi, M.Sc., collected the data; Mehdi Nasiri Sarvi, Assistant Professor, contributed to the analysis of the results. 